that such information could probably have been very well omitted, due to its availability elsewhere. Interwoven throughout this discussion, however, are references to certain basic tools and publications of particular relevance to the area of mathematics and physics. It is precisely this portion of the presentation which, though probably adequate, could have been profitably expanded in view of the previously uncharted nature of the field. The section on periodicals is notably anl lamentably brief.

The second and more valuable part of this guide consists of a bibliography of more than 2000 titles, including books and some periodical articles. The latter consist mainly of references to Reviews of Modern Physics, of which the first 17 articles are said to be indexed here. The content of the bibliography falls predominantly within the area indicated by the title of the volume, with emphasis on basic and fundamental-though by no means elementary-publications, which can serve as starting points for further reading. Related engineering and general scientific literature is well represented, though with an occasional unevenness and incompleteness due probably to limitations of space and time. The material is arranged under 150 carefully chosen and specific subject headings, most of which are described or defined briefly with an occasional indication of the kind of literature available in the specific area. Unfortunately there are only a few brief annotations of individual titles and even these are sometimes as short as three or four words. The annotations given are suprisingly helpful and meaningful despite their brevity. The usefulness of the bibliography is increased by the inclusion of a good author index, but is decreased by the lack of a sufficiently detailed index.

Reference librarians will find the bibliography of particular value as it affords a more direct and convenient approach to some of the material than does the library catalog. Some use could also be made of this volume in the building up of a basic collection in the areas covered, though prices are not given and many of the books listed are not readily available. It should always be remembered that the value of a subject guide is limited somewhat due to the rapidly changing nature of the field, and hence continuous supplementary use must be made of current periodical literature. As a guide to important material which exists today, this is a valuable and helpful work.-Robert E. Maizell, New York Public Library.

\title{
Engineering Information
}

Sources of Engineering Information. By Blanche $H$. Dalton. Berkeley and Los Angeles, University of California Press, 1948, rogp. \$4.00.

This is an excellent beginning for a muchneeded work in engineering and technology. It is a manual on the reference sources of the field; a field whose wealth of material bewilders even the experienced. It is also a pioneer work in that it is virtually the first of its kind to cover technology and engineering from the American point of view. It leaves much to be desired, but the author is to be congratulated on her enterprise and courage in undertaking this formidable project.

In the preface, the author refers briefly to two works: A. D. Robert's Guide to Technical Literature (1939) and Dr. J. Edwin Holmstrom's Records and Research in En- gineering and Industrial Science (1940). ${ }^{1}$ Neither of these is competitive. The former is better organized and written but emphasizes European material. The latter is a work of description and constructive discussion written by a scientist and engineer in his own right. In content and literary merit, it will delight and fascinate both the practical technologist and engineer as well as the most erudite scholar. It is not, however, a reference manual in the sense that Mrs. Dalton's book is.

Sources of Engineering Information is a classified guide to titles accompanied usually by a one-line annotation. Unquestionably the best section in the entire work is number II on "Abstracts," 2 p. 4-15. To begin with

\footnotetext{
1 The second edition, revised and enlarged, came out

${ }^{2}$ For a fine survey and review on this subject, see
} 
are the more general; then follow the special arranged by subject. It should be pointed out that the former "Current Metallurgical Abstracts" of Metals and Alloys has two cumulative indices covering 1929-34 and after that annual indices through 1942 , with which this fine abstracting service goes into oblivion.

Section I on "Indexes to Periodical and Serial Literature" is considered second best. To this should be added Donald C. Haskell's A Check List of Cumulative Indexes to Individual Periodicals. ${ }^{3}$

Section III on "Location of Articles; Identification of Periodicals" is reasonably extensive and no doubt quite adequate for the purposes of this bibliography. Since, however, the Bibliography of Scientific and Industrial Reports is listed (p.23), it would not have been out of order to have listed Grace Swift's Government Document Series Analyzed by the Office of Technical Services (1947), which lists the serials abstracted in that work. Also it is to be regretted that the third edition of Union List of Technical Periodicals (1947) 4 is not included. There are, to our knowledge, over 600 references in this field alone, and the most extreme selectivity can be exercised.

Sections IV and V, "Bibliography" and "Reference Books" respectively, might well have been grouped, as both cover about the same ground. A grave omission from the former is the Bibliographic Index, which lists a number of bibliographies in the sciences and in technology. Under "Metals" is listed John L. Haughton's Bibliography of the Literature Relating to the Constitutional Diagrams of Alloys (1942); this should have been listed under "Alloys," as such diagrams in metallurgy deal only with alloys. Max Hansen's Der Aufbau der Zweistofflegierungen (1936, Edwards Bros., 1943) and Ernst Jänecke's Kurzgefasstes Handbuch Aller Legierungen (1937, Edwards Bros., 1943),

E. R. Francis' "Metallurgical Literature: Its Coordination and Diffusion" in the Foundry Trade Journal (London) Mar. 19-Apr. 16, 1942, Vol. 66, no. 1335, p. 177-179; no. 1336, p. 195-197, 194; and discussion, no. 1339, p. 245,244 . "An excellent review, dealing for the most part with the various abstracting services covering the field of metallurgical literature."

New York Public Library, r 942

4 Compiled by Elizabeth Gilbert Bowerman for the Science-Technology Group of the Special Libraries Association. both on constitutional diagrams of alloys, should have been listed under "Alloys" in one or the other of these two sections. In addition, reference could also have been made to the extensive sections on this subject both in the International Critical Tables (p.92) and in Landolt-Börnstein Physikalisch-chemische Tabellen (p.92).

Section VI, the "Trade Catalog Collection," is limited to one page.

Section VII, on "Standards and Specifications," is an excellent listing of institutions and offices relating to these topics.

Patent literature is conspicuous by its absence. Since patent literature in technology and the sciences precedes periodical literature by two or three years ${ }^{5}$ and since there were approximately 200,000 patents issued annually before the war, this becomes a vital source, and often the only source, of technological information. It should not be ignored.

Throughout the work only monographs and sets are listed. Periodical articles, regardless of their contents or merits, are not included. There are no indices of any sort. At times titles are inconsistently repeated under different subjects. The latter is especially true for Sections IV (Bibliography) and V (Reference Books).

The classification is based on form rather than subject. As a consequence anyone making the subject approach must use his ingenuity, as he may find his references scattered throughout several sections of the book as well as under different subheadings of the same section.

Engineering librarians, engineers and technologists will welcome this work both as a survey of the field and as a guide in searching the literature. May we lend, every encouragement to the author to continue. Future editions should double or even treble the size of the present volume. Also we would like to see them classified by subject rather than form, with more complete titles and bibliographical data, fuller annotations, and author and subject indices.-Emory $C$. Skarshaug, Federal-Mogul Research \&๐ Development, Ann Arbor.

\footnotetext{
${ }^{5}$ Estimation of J. Alingh Prins quoted by Holm.
} strom, supra p. 202. 